\title{
The impact of implementing a person- centred pain management intervention on resistance to change and organizational culture
}

Eva Angelini ${ }^{1,2,3^{*}}$ (D) Axel Wolf ${ }^{2}$, Helle Wijk ${ }^{2,4,5}$, Helena Brisby ${ }^{1,6}$ and Adad Baranto ${ }^{1,6}$

\begin{abstract}
Background: Resistance to change and organizational culture are essential factors to consider in change management in health care settings. Implementation of structural change remains a challenge. There is a lack of studies providing information on the impact of implementation processes on the organization. The aim of this study was to describe the impact of implementing a systematic change process concerning postoperative personcentred pain management on resistance to change and organizational culture in an orthopaedic spine surgery unit.

Methods: The study was set in an orthopaedic spine surgery unit at a university hospital. Person-centred bundles of care for postoperative pain management of spine surgery patients were developed in co-creation by a multiprofessional expert group and implemented throughout the care pathway. The intervention was underpinned by theories on organizational culture and inspired by principles of person-centred care. Quantitative data were collected using the Resistance to Change Scale and the Organizational Culture Assessment Instrument and analysed using descriptive statistics.

Results: The findings showed a low resistance to change decreasing during the study. The organizational culture shifted from a result-oriented to a formalized and structured culture after the implementation. The culture preferred by the staff was team-oriented and participation-focused throughout the study. The discrepancy between the current and preferred cultures remained extensive over time.

Conclusion: It is challenging to describe the influence of the development and implementation of a postoperative pain management program on organizational culture as well as in terms of resistance to change, in a complex health care setting. In the current study the unit was under organizational strain during the implementation. Albeit, the important discrepancy between the current and preferred organizational culture could imply that structural changes aren't enough when implementing person-centred pain management structures and needs to be combined with relational aspects of change.
\end{abstract}

Keywords: Resistance to change, Organizational culture, Organization, Person-centred care, Implementation, Spine surgery

\footnotetext{
* Correspondence: eva.angelini@vgregion.se

'Department of Orthopaedics, Institute of Clinical Sciences, at Sahlgrenska Academy, University of Gothenburg, Gothenburg, Sweden

${ }^{2}$ Institute of Health and Care Sciences at Sahlgrenska Academy, University of Gothenburg, Gothenburg, Sweden

Full list of author information is available at the end of the article
}

C C The Author(s). 2021 Open Access This article is licensed under a Creative Commons Attribution 4.0 International License, which permits use, sharing, adaptation, distribution and reproduction in any medium or format, as long as you give appropriate credit to the original author(s) and the source, provide a link to the Creative Commons licence, and indicate if changes were made. The images or other third party material in this article are included in the article's Creative Commons licence, unless indicated otherwise in a credit line to the material. If material is not included in the article's Creative Commons licence and your intended use is not permitted by statutory regulation or exceeds the permitted use, you will need to obtain permission directly from the copyright holder. To view a copy of this licence, visit http://creativecommons.org/licenses/by/4.0/. The Creative Commons Public Domain Dedication waiver (http://creativecommons.org/publicdomain/zero/1.0/) applies to the data made available in this article, unless otherwise stated in a credit line to the data. 


\section{Background}

In this paper, our focus is on understanding implementation processes by describing the effect of a change process on resistance to change (RTC) and organizational culture (OC) in an orthopaedic surgery setting in a large university hospital. Health care organizations (HCOs) have an obligation to maintain and safeguard high quality through continuous improvement, and so are submitted to constant change to meet demands for improved quality, safety and efficiency. The task of introducing change into overburdened and complex organizations such as in health care is challenging as these settings are large in scale and divided into specialized fields. Moreover, HCOs can develop fatigue with constant changes, leading to resistance to change, and in fact change in health care is often met by resistance [1]. According to Peiperl (2005, p. 348) [2], RTC is "active or passive responses on the part of a person or group that militate against a particular change, a program of changes, or change in general". RTC is mostly described as resistance on an individual basis, but Curt Lewin who introduced the concept in 1930, followed by Coch and French, considered that RTC does not arise from the unique individual but from the context in which the change takes place [3]. According to Lewin, the individual's behaviour is a product of a complex system, an organization, forming a force field around the individual [4]. This is of relevance in a study like the present where the survey is completed by individuals in a $\mathrm{HCO}$ and then aggregated and analysed as one.

An organizational culture can be described as fluid and hard to grasp as it lies under the surface of what is seen and tangible, reflecting the underlying values and shared assumptions within an organization [5]. In health care, the concept has been used for decades $[5,6]$. OCs may be contributing factors in poor change implementation. Every organization has its unique culture specific to each lone workplace. The concept of organizational culture originates in the social sciences where the underlying assumption that an organization can be seen as a miniature society and justifies a cultural approach. According to Michie and Williams [7], hospital wards develop their own local OCs. In this study, we were interested in observing a specific ward's underlying $\mathrm{OC}$ during structural change, as Resistance to change and organizational culture may impede organizational development and change in health care [8].

Person-centred care (PCC) is an approach including the patient as an equal partner and stakeholder in health care [9]. It has gained increasing interest as a way to empower patients and improve quality. When operationalizing PCC, deliberate (i.e. planned) strategies are important to consider, as are emergent strategies (i.e. in response to the specific change process) [10]. PCC goes beyond the relationship between patient/person and health care staff to affect intra-professional relations. Moore et al. identify barriers and facilitators when implementing PCC. Barriers may include professionals' attitudes when implementing PCC as it is easier to employ habitual care routines; facilitators include strong leadership which is important when converting to PCC [11].

Resistance to change, organizational culture and person-centred care are constructs of importance in quality improvement. PCC has shown to have organizational impact; Alharbi et al. [12] identified factors facilitating or obstructing the implementation process including organizational culture, resistance to change and time and rapidity of implementation. Further, Wolf et al. [13] found that health care units reached a higher cultural uniformity after implementing person-centred care. Yet the impact of change in health care regarding person-centred care are not fully explored. Considering the paucity of research on the impact of change processes on RTC and OC. This study sought to understand if and how change processes affect RTC and OC over time in an orthopaedic health care setting.

\section{Aim}

The aim of this study was to describe the impact of implementing a systematic change process concerning postoperative person-centred pain management on resistance to change and organizational culture in an orthopaedic spine surgery unit.

\section{Methods \\ Design}

This study has a descriptive, cross-sectional survey design, and is part of a larger research project $[14,15]$. The present study consists of a pain management intervention and its' implementation. The overall change programme design was guided by the integrated Promoting Action on Research Implementation in Health Services (i-PARIHS) framework [16] to explore the impact of the change process on resistance to change and organizational culture. The core constructs in the iPARIHS framework are innovation, recipient, context and facilitation [16]. The method section will hereby follow the iPARIHS structure as follows.

\section{Innovation}

The overall focus in this study was to give greater attention to patients' postoperative pain management after elective lumbar spine surgery by including the patients' narratives and documenting these in medical records to give more coherent care adjusted to each patient. The rationale for the intervention was the lack of a defined 
structure for dealing with patients' pain and pain management after planned lumbar spine surgery. This leads to incoherent pain treatment, hence the aim to build structures supporting PCC. An expert group was formed with the purpose of improving postoperative pain management in the unit by implementing a PCC approach. The group members represented health professions involved in postoperative pain management. They had knowledge of PCC but no previous training in PCC. The group comprised representation from: first-line management, orthopaedic surgeons, physicians in training, registered nurses (RN), physiotherapists (PT), and assistant nurses (AN). A total of nine experienced professionals were active in the group simultaneously, representing approximately $15 \%$ of the total workforce. The assistant doctors changed over time as they worked in the service for about 6 months; RNs changed likewise due to nurse turnover.
The expert group commenced by mapping usual care and the researchers then subsequently developed the intervention together with the expert group. This study extends over a substantial period, March 2017 to March 2020: major organizational events was registered through observation by group members and are shown on a timeline (see Fig. 1). The group met intensively during the co-creation, 10 meetings being held between April and November 2018. In 2019, the group continued to meet regularly to maintain and evaluate the change programme. In addition to the expert group, a group of physicians of diverse seniority and experience met in three sessions in late 2017 to develop routines for patients' written discharge summaries (required by Swedish legislation since 2012) [17], which had at the time of initiation of the study not been employed in the unit. The group of physicians also established templates specific to

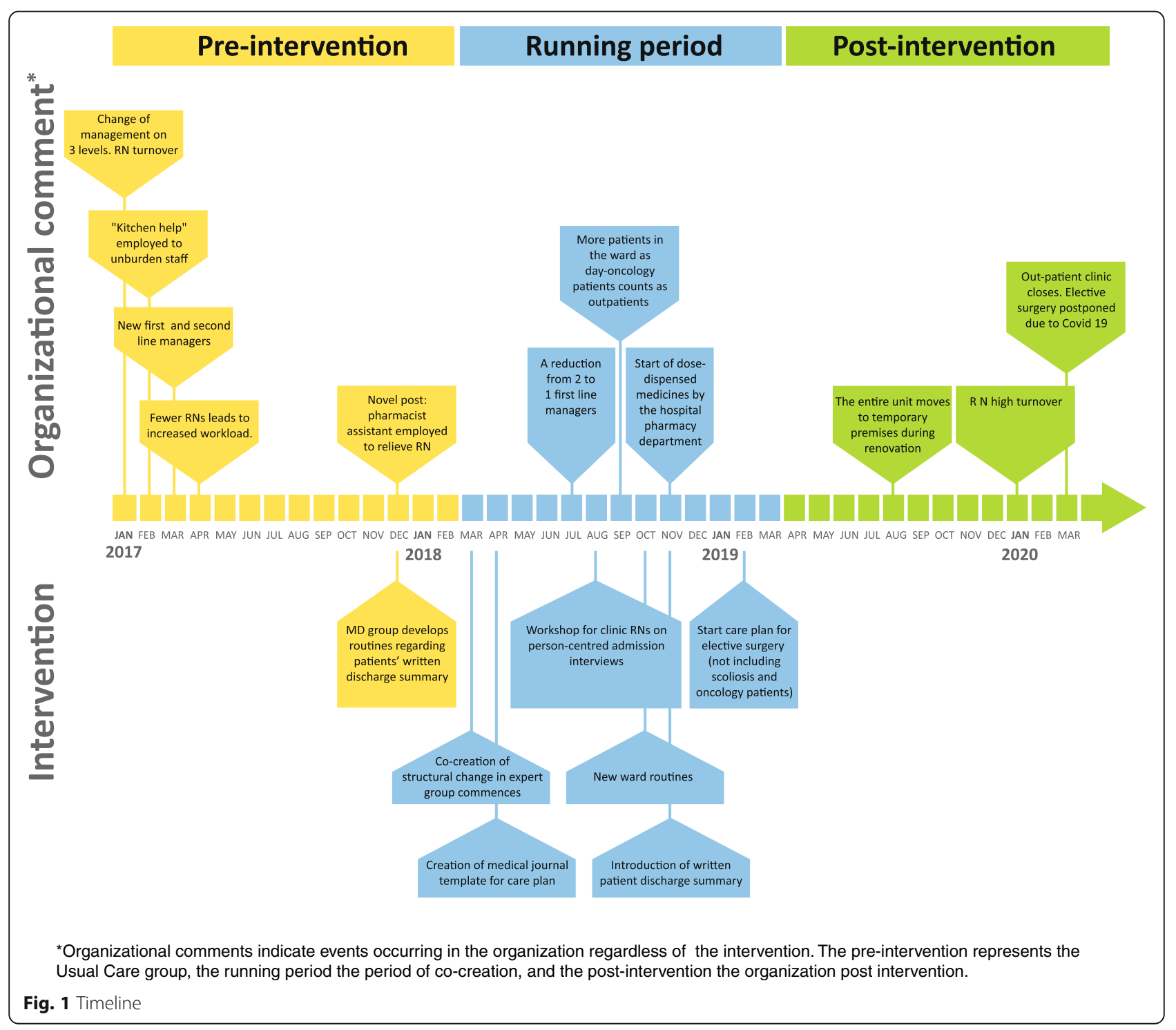


the diverse surgeries performed within the unit, to serve as starting points and to be personalized at discharge.

The mapping of the unit revealed the following:

- The documentation in the medical record was fragmented and incoherent, leading to difficulty in following the patient's reported pain and pain management.

- The daily round was experienced as stressful and seen as inadequate and inefficient by the care staff. The round hampered care as its timing was unpredictable, while decision-making was protracted since assistant doctors were alone while the orthopaedic surgeons were in the operating theatre or in the out-patient clinic. This led to patients not receiving optimal care [14].

- At discharge, no routine existed for patients to receive written information about care given during the hospital stay nor about care after discharge.

The tailoring of the structural change commenced after the mapping, and after multiple sessions in the expert group, a bundle of PCC activities was established, together with implementation strategies for each (Table 1). It presented a care pathway allowing a more articulate focus on patients' pain management. The timings for implementing each part of the intervention are found in the timeline (Fig. 1). In addition to the expert group, other expertise was employed to develop a documentation template for a care plan with focus on postoperative pain management. The hospital IT and medical records departments were engaged to do this.

\section{Recipients}

The staff comprise physicians, care staff and administrative personnel. All staff working in patient care were asked to participate.

\section{Context}

This study was conducted in a ward specializing in spine surgery at a university hospital in Sweden. In the unit the patients are cared for consists of electively spine surgery patients, spine trauma patients, and orthopaedic oncology patients, including children and adults.

\section{Facilitation}

Each member of the expert group acted as a change agent and facilitator for each phase of the construction and implementation of the change programme, mainly in his or her professional group, thus having the ability to sustain colleagues' efforts. Facilitators also observed the implementation process, reporting back to the expert group in order to adapt it to the current situation in the unit.

\section{Theoretical framework}

Initially, the Competing Values Framework (CVF) was developed in research studying key factors in effective organizations. This was followed by Quinn and Rohrbaugh further analysing and identifying key factors of effectiveness. The framework consists of two major dimensions of organizational approach: internal focus and integration versus external focus and differentiation: and flexibility and discretion versus stability and control. These form a square divided into four quadrants where

Table 1 An overview of the intervention and implementation

The pain management intervention
Admission interview with the patient/RN regarding pain.
The novel routine: The RN obtained the patient's narrative at the pre-
admission visit, including information regarding everyday life and the im-
pact of pain prior to the planned surgery. The narrative was summarized
in a care plan, with other clinical information. A tentative PCC plan was
written by the RN, including the patient's recovery goal and expected
length of stay. The PCC plan was finalized and updated the evening be-
fore planned surgery when the patient was admitted.
Care plan with focus on pain and pain management.
The novel routine: Continuous documentation of pain and pain
management in the care plan following the guideline. All staff were able
to use the plan.
Round routine with explicit roles.
The novel routine: Checklist and precise timings for the round. All
professions to be present at the round. MD to lead the round according
to checklist; RN to document a summary in the care plan.

Written patient discharge summaries.

The novel routine: Ward secretaries were assigned to add the template to patients' journals, and the physician at discharge was responsible for adjusting it to the patient.

\author{
The implementation \\ Two workshops in autumn 2018 and one in February 2019 were held \\ with RNs in the outpatient clinic, hosted by RN expert in PCC. As new \\ RNs started in the clinic, they received information and training in PCC \\ and documenting patients' narratives.
}

A flowchart to use as a guideline was developed by the RNs in the expert group. RNs in the outpatient clinic and the ward were informed of the use of the care plan, starting in February 2019.

As all professions were represented in the expert group, relevant professional issues regarding the round emerged in discussions. Professional differences of opinion mostly concerned the timing and the importance of the round. A routine was established by consensus after multiple sessions, and then agreed with relevant first line managers before starting in October 2018.

Routines for templates were established. Started in November 2018. 
each quadrant represents a prominent archetypical organizational characteristic, i.e. culture type. Each quadrant represents basic assumptions, orientations and values characterizing an organizational culture. As the name of the framework indicates, the quadrants compete with each other. The competition is diagonal: thus, the upper left quadrant, clan, is in competition with the lower right quadrant, market, while the upper right, adhocracy, competes with the lower left, hierarchy. Below follows a brief explanation of the four culture types:

\section{The clan culture (CC)}

In this organization, people have a lot in common. Friendships are strong and the unit feels like a big family. The organization promotes teamwork, participation, and consensus.

\section{The adhocracy culture (AC)}

The organization is dynamic, entrepreneurial, and creative. The organization values individual initiative and freedom.

\section{The market culture (MC)}

The organization is result-oriented. Reaching goals and gaining a reputation of success are important.

\section{The hierarchy culture (HC)}

The organization is a formalized and structured workplace. Procedures direct what people do. Work should be efficient and smooth. Stability and results are key.

No cultural type is valued as superior to another; nevertheless, it has been seen that a balanced mixture of $\mathrm{OC}$ types is favourable in change processes in HCOs and drives sustainability i.e. the organization's capacity to sustain change over time [18] (Fig. 2).

\section{The survey}

The questionnaire consists of two instruments: The Resistance to Change Scale and The Organizational Culture Assessment Instrument.

\section{The resistance to change scale}

The dispositional Resistance to Change Scale (RTCS) was used to assess the staff reactions to imposed change. In 2003, Oreg [19] developed and validated the scale to establish the existence of disposition to resist change to predict reactions to specific change. The scale was available in a Swedish version. The scale covers the following four factors of an individual's inclination to resist change:

- Routine seeking (RS)

- Emotional reaction to imposed change (ER)

- Short-term focus (STF)

- Cognitive rigidity (CR)

These factors reflect behavioural, affective, and cognitive aspects of resistance to change.

The behavioural dimension RS reveals people's inclination to adopt routines. The affective dimension contains ER and STF: ER mirrors the extent of perceived stress and uneasiness the individual experiences when faced with change; STF reflects an individual's disposition to accept the immediate inconvenience of change in order to obtain a long-term benefit. The cognitive dimension CR relates to dogmatism: change is resisted due to rigidity and a closed mind-set. RTCS scores range from 0 (no resistance) to 6 (maximum resistance) [19].

\section{The organizational culture assessment instrument}

The Organizational Culture Assessment Instrument (OCAI), based on the CVF developed by Cameron and

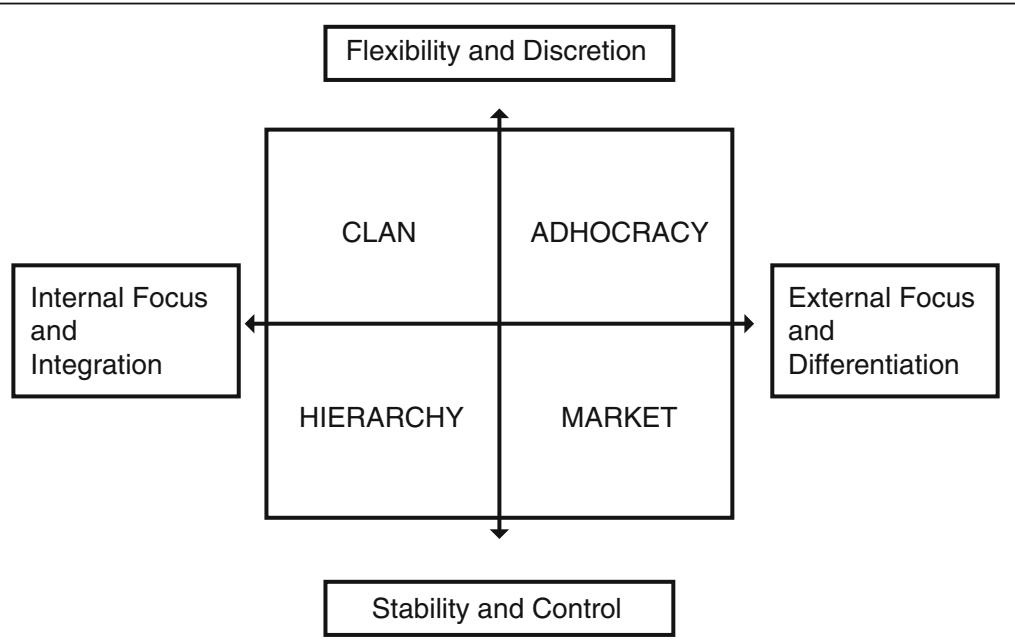

Fig. 2 The Competing Values Framework [18] 
Quinn, was used to assess OC [18]. The instrument is validated and has been shown to have psychometric validity, albeit weaker with regard to preferred culture [20].

The instrument is widely used, including in health care [21]. The instrument measures the current culture, as well as the preferred culture (i.e. how the respondent would like the unit to be in 5 years in order to be successful) and displays the differences between the current and the preferred cultures. According to Cameron and Quinn, differences larger than 10 points require rapid action [18]. The instrument has an ipsative (forced choice) scale: the respondent divides 100 points between four alternatives in each domain, giving the highest points to the alternative most similar to their organization and decreasing the points as the alternatives differ more and more.

Since there was no Swedish version of the OCAI, a translation was made using the COSMIN checklist for cross-cultural validity [22] (permission granted by the developers of the instrument). The OCAI was translated from English into Swedish by two independent translators, one with and one without expertise in this topic. The Swedish translation was then backtranslated by two independent professional language editors blinded to the original version. Differences were solved by consensus between the translators. Based on this translation, an interdisciplinary expert group was established consisting of an expert in implementation in health care, an orthopaedic surgeon, a specialist nurse, an associate professor, and the authors of the instrument, Kim Cameron and Robert Quinn. Furthermore, one male and one female registered nurse $(\mathrm{RN})$, representing the target population, checked the translation's coherence in health care environments. There were minor differences between the original and back-translated versions comments which were resolved by the expert group and synthesized into a final Swedish version, where after a pilot study was conducted in an adjacent ward. The pilot was not included in the current study. No major changes were necessary after the pilot study.

\section{Procedure}

Participants received verbal and written information explaining the aim and procedure of the study, together with informed consent forms and self-report questionnaires from the first author (EA). Participation was voluntary. Age and profession were retrieved from the consent forms. Tenure and number of years in profession were collected by the first author (EA). Two reminders were sent by mail 2 and 4 weeks after the due date). Completed questionnaires were returned in allocated binders, with respondents' anonymity being maintained.

The survey included several measures, with six time points stretching over 2 years and 9 months. The findings were to be presented with baseline, the preintervention, (based on four time points exploring the organizational baseline over time: March, June, September 2017, and March 2018), covering the year preceding the start of the change programme. This was to be followed by the period when the change programme was developed, the running period, (September 2018 - one time point), and post-implementation (October to November 2019 - one time point).

Staff working in the ward could respond 1-6 times to the survey. The first time a participant responded, consent and demographic data were collected. At each time point, paper surveys in pre-labelled envelopes were distributed by contact persons, i.e. the ward-coordinator and the secretary in the doctors' office. The survey went to RNs, ANs, and physicians working $50 \%$ or more of a full time at the unit. Managers were not included in the survey.

\section{Ethics}

The Regional Ethical Review Board approved the study (ID number 124-16), which conforms to the principles of the Declaration of Helsinki [23].

\section{Statistical analysis}

Descriptive statistics were presented as mean and standard deviation (SD), or median and interquartile range (IQR) as appropriate. Normality of data was inspected visually by histograms and by the Shapiro-Wilk test.

\section{Results}

In the present study, resistance to change and organizational culture were measured over time parallel to the implementation of structural change. Our findings are presented with regard to the organization as a whole, the staff's individual scores being aggregated into one overall score.

In total, 353 questionnaires were distributed, of which 198 were returned (56\%). The RTCS had 198 correct and valid questionnaires. For the OCAI, questionnaires with miscalculations were excluded, the final number being 143. Of the 198 surveys were all used for the RTCS but only 143 were valid for the OCAI.

\section{Study population}

In total, 119 staff were asked to participate and 81 (68\%) did so: demographic data are presented in Table 2.

\section{Timeline}

HCOs are complex so we have assembled a timeline to indicate important parameters or events occurring in the unit which imply organizational strain. Our findings are presented in relation to events occurring in the unit (see Fig. 1). 
Table 2 Participant demographics

\begin{tabular}{lll}
\hline & Frequency & Percent \\
\hline Sex & & \\
Male & $36 / 81$ & 44 \\
Female & $45 / 81$ & 56 \\
Age, mean (SD) & $40(12.7)$ & \\
Age groups & & \\
20-29 & $19 / 81$ & 23 \\
30-39 & $24 / 81$ & 30 \\
40-49 & $16 / 81$ & 20 \\
50-59 & $16 / 81$ & 20 \\
60-69 & $6 / 81$ & 7 \\
Professionals & & \\
Assistant RN & $25 / 81$ & 31 \\
RN & $23 / 81$ & 28 \\
Assistant PT & $1 / 81$ & 1 \\
PT & $3 / 81$ & 4 \\
Assistant doctor & $6 / 81$ & 7 \\
Resident doctor & $9 / 81$ & 11 \\
Orthopaedic surgeon & $14 / 81$ & 17 \\
Experience & & \\
Professional experience, median (IQR) year & $9(4-22)$ & \\
Tenure, median (IQR) year & $1.2(0.2-8.5)$ & \\
\hline
\end{tabular}

Percentages may not sum to 100 due to rounding

\section{Resistance to change}

In total, 198/353 (56\%) complete RTCS questionnaires were returned: the lowest response rate for the different stages was $52 \%$ (see Table 3 ).

The findings show a stable, rather low, resistance to change, slightly declining over time. The mean RTCS scores, as well as all of four of its factors, reduced over time. CR gave the highest scores, revealing some degree of dogmatism where the organization resists change due to rigidity and closed mind-sets. On the other hand, STF had the lowest scores, reflecting a disposition to accept an immediate inconvenience of change in order to obtain a long-term benefit. Further, ER and RS clustered close to the mean RTCS scores (see Table 4).

\section{Organizational culture}

In total, $143(40.5 \%)$ complete OCAI questionnaires were returned: 96 from the baseline group, 24 from the running period, and 23 post-intervention. The OCAI

Table 3 Response rates

\begin{tabular}{llll}
\hline & Baseline & Running period & Post-intervention \\
\hline Frequency & $132 / 239$ & $34 / 52$ & $32 / 62$ \\
Percent & 55 & 65 & 52 \\
\hline
\end{tabular}

measures three facets of OC: the current or "the now", the preferred, and the discrepancy between the current and the preferred.

\section{The current culture}

At baseline, the market culture is narrowly the dominant one, representing goal achievement and success, though the clan and hierarchy cultures score almost as highly. Adhocracy received the lowest score. Post-intervention, hierarchy is the more dominant culture, representing a dominance of structure, procedures, efficiency and predictability. Hierarchy is closely followed by market, then clan and lastly adhocracy. Thus, the current culture displays a balanced mixture of cultures over time with a slight emphasis placed on results and profitability.

\section{The preferred culture}

At baseline, clan culture is the dominant preferred culture, representing friendship, teamwork and participation. Clan was followed by the adhocracy and hierarchy cultures. The market culture received the lowest score. Post-intervention, clan remains dominant, followed by hierarchy and adhocracy. The market culture remains the lowest scoring.

\section{The discrepancy between the current and preferred cultures}

At baseline, there is a discrepancy between the dominant current culture, market (27.61, Table 5), and the dominant preferred culture, clan (34.94, Table 6). In the postintervention group, the discrepancy is now between the dominant current culture, hierarchy (30.06, Table 5), and the dominant preferred culture, clan (33.58, Tables 5 and 6). Further, the market culture displays the largest discrepancy between the current and preferred measures (Tables 5 and 6). Thus, there is a persistent and obvious gap between current and preferred cultures, with the discrepancy between market and clan persisting over time.

\section{Discussion}

The current study describes the effect of an implementation of a systematic change process concerning postoperative person-centred pain management on resistance to change and organizational culture in an orthopaedic spine surgery setting. These findings show multiple organizational events indicating organizational strain, a rather low but stable and slightly descending RTC, and a stable and balanced mix of $\mathrm{OC}$, with nonetheless a considerable discrepancy between the current and preferred cultures.

Person-centred care has seen a remarkable increase over recent years: for example, in the current orthopaedic ward, Angelini et al. found staff wanting 
Table 4 RTCS scores

\begin{tabular}{|c|c|c|c|c|c|c|}
\hline & \multicolumn{6}{|l|}{ Group } \\
\hline & \multicolumn{2}{|c|}{ Baseline } & \multicolumn{2}{|c|}{ Running period } & \multicolumn{2}{|c|}{ Post-intervention } \\
\hline & Mean & SD & Mean & SD & Mean & SD \\
\hline RTCS & 2.62 & 0.46 & 2.68 & 0.56 & 2.46 & 0.56 \\
\hline Routine seeking & 2.49 & 0.57 & 2.56 & 0.50 & 2.40 & 0.61 \\
\hline Emotional reaction & 2.59 & 0.79 & 2.80 & 0.91 & 2.40 & 1.16 \\
\hline Short-term focus & 2.11 & 0.78 & 2.14 & 0.88 & 1.89 & 0.70 \\
\hline Cognitive rigidity & 3.32 & 0.68 & 3.24 & 0.80 & 3.18 & 0.70 \\
\hline
\end{tabular}

increased opportunities for adapting care to each patient to give a more personalized approach [15]. The amplified demand for PCC entails structural change, but this does not automatically lead to cultural change. $\mathrm{OC}$ is frequently talked about as the overarching factor when addressing quality in health care. On the other hand, it is commonly identified as the villain that needs to be tackled in order to solve organizational issues. Mannion and Davies imply that the influence of OC can be overemphasized [24]. In the present study, we looked at OC change over a 2.5- year period, a substantial time in an HCO. The timeline lists multiple organizational events leading to organizational strain. Despite these events (changes in management, staff turnover etc.), RTC and OC basically remained stable (Table 3 ). The events presented as organizational strain on the timeline are not exceptional for HCOs in general, these being involved in a constant demand for change with a focus on quality. Health care organizations are subject to multifaceted challenges from both internal and external contexts. Nilsen and Bernhardsson highlight the importance of, but difficulty in, addressing the influence of the external context on change [25]. In the current research, it is likewise difficult to distinguish the impact of both internal and external contexts.

Our findings reveal a rather low RTC with an overall reduction over time, indicating an increased readiness for change. The shift to a dominant culture of hierarchy, with clearer roles being a prerequisite for higher quality, is consistent with the findings of Wolf et al. who found that a culture of routines and structure increased when

Table 5 OCAI The current measure

\begin{tabular}{|c|c|c|c|c|c|c|}
\hline & \multicolumn{6}{|l|}{ Group } \\
\hline & \multicolumn{2}{|c|}{ Baseline } & \multicolumn{2}{|c|}{ Running period } & \multicolumn{2}{|c|}{ Post-intervention } \\
\hline & Mean & SD & Mean & SD & Mean & SD \\
\hline Clan now & 26.98 & 12.29 & 21.49 & 12.98 & 22.36 & 12.37 \\
\hline Adhocracy now & 19.10 & 6.04 & 16.60 & 5.85 & 18.36 & 7.32 \\
\hline Market now & 27.61 & 9.91 & 28.73 & 14.10 & 29.21 & 13.31 \\
\hline Hierarchy now & 26.24 & 8.82 & 33.40 & 10.54 & 30.06 & 12.65 \\
\hline
\end{tabular}

implementing structured person-centred care. In contrast to our findings, Jones and Van de Ven found that RTC increased over time leading to a weaker commitment to the organization and perception of reduced organizational effectiveness [26]. Likewise, it has been found that planning, routines and goal setting (market and hierarchy cultures i.e. stability and control) appeared to increase RTC [8]. Further, Naldermirci et al. studied deliberate and emergent strategies when implementing person-centred care [10]. In our study, the expert group developed emergent strategies as clinical practice was continuously adapted in the unit during the co-creation of structural change. Jones and Van de Ven found that supportive leadership could reduce RTC [26]. One known factor in achieving change is engaged and strong leadership [11, 27]. Management was represented in the expert group but communication with and engagement from executive management outside the expert group was feeble.

In the current study, OC was observed in order to detect a possible influence on $\mathrm{OC}$ when implementing PCC structures. The discrepancy between the current and preferred OCs was extensive and persistent over time, with the dominant preferred culture being the clan culture. The discrepancy implies a strong and persistent desire for culture change, from stability and control to a more person-oriented culture. These results further demonstrate that under organizational strain the preferences for the OC remain stable. This persistent gap might indicate that the implementation itself not systematically applied person-centredness for staff

Table 6 OCAI The preferred measure

\begin{tabular}{|c|c|c|c|c|c|c|}
\hline & \multicolumn{6}{|l|}{ Group } \\
\hline & \multicolumn{2}{|c|}{ Baseline } & \multicolumn{2}{|c|}{ Running period } & \multicolumn{2}{|c|}{ Post-intervention } \\
\hline & Mean & SD & Mean & SD & Mean & SD \\
\hline Clan Pref & 34.94 & 9.26 & 36.56 & 13.83 & 33.58 & 12.09 \\
\hline Adhocracy pref & 23.08 & 5.17 & 22.75 & 8.45 & 22.29 & 5.25 \\
\hline Market pref & 19.29 & 6.21 & 16.90 & 8.95 & 19.06 & 5.97 \\
\hline Hierarchy pref & 22.68 & 6.45 & 23.31 & 12.96 & 25.00 & 8.54 \\
\hline
\end{tabular}


throughout the change process. The importance of a systematical approach has been shown in Ekman et al. [28]. Did the implementation merely attain a structurally based change and not a relational change? A greater focus on relational change might have been achieved with an intensified emphasis on person-centredness within the expert group and increased facilitation within the organization. The i-PARIHS framework has facilitation as a major construct, but the framework lack a person-centred construct. We believe that the framework may benefit from adding person-centredness, between facilitators as well as with the staff. Facilitations needs to impact both structure and relations within the organization by dialogue and partnership building, i.e. person-centered facilitation. Thus, the framework might reach further and attain a more sustainable impact. Facilitating change is complex, as facilitators must balance the groups' different perspectives and attitudes regarding resistance to change. And while resistance, and consequently RTC, is generally seen as something negative, a growing body of research questions whether this is always the case $[29,30]$. A lack of RTC could hinder sustainability in quality as no scrutiny of the change would take place. This could be potentially harmful as, without sustainability, continuity could not be achieved. Oreg sought through three studies to link performance and RTC, his findings revealing that resistant individuals were good at routine and monotonous tasks but not at non-routine tasks. This gave stability to routine work [31] which could be valuable in HCOs, where routine work is a large and fundamental part of their work. Further, Amarantou et al. [32] searched for factors affecting RTC and found that it was influenced by both individual and organizational factors, mediated by employee participation in the decision-making.

\section{Limitations and strengths}

A methodological limitation to the study could be the use only of a quantitative method, as the nature of the organizational culture is complex, this construct might have demanded a mixed methods design: future studies should include qualitative methods in order to get a fuller picture of a specific unit. Nevertheless, patients in the unit were interviewed in focus group interviews prior to the intervention, the result of Angelini et al. [14] was discussed with and guided the expert group in the current study. However, patients were not part of the expert group. On the other hand, a strength in our study is the careful choice of questionnaires, only validated instruments previously used in health care being selected $[19,33]$.

Our findings emerged from a relatively low participation rate but survey reluctance is an increasing phenomenon [34]. The OCAI was chosen as it was a validated and well-established instrument albeit not translated into Swedish. The translation described in the current study was challenged with the culture aspect of health care in the origin context of the instrument (USA) and Sweden, being two different cultures. Another issue was the generic culture aspect of the instrument not developed for health care in particular. In addition, health care in Sweden is in large non-profit therefore production and market aspects are infrequent concepts. Additionally, some staff found the OCAI timeconsuming, adding to existing stress, as staff felt they did not have time to fill out the questionnaire during working hours. Further, the OCAI's ipsative scale was a problem as we had to exclude $>50$ questionnaires due to miscalculations. The difference in the final numbers of RTCS and OCAI is problematic and might have weakened the interpretation of the result as the RTC score is based on a larger base than the OC score. An online version would have prevented this problem, as this would have indicated miscalculations immediately. The design also entailed some respondents' having answered several times, perhaps limiting the breadth of data. However, our goal was to survey the organization as a whole and not professionals, with their groups and subcultures.

Further, the participants median tenure in the unit were 1.2 years. In general, younger staff and staff in training change units, whereas, senior staff tend to be less mobile, here displayed in the vast IQR $(0.2-8.5)$ years.

\section{Conclusions}

Complexity is inherent in large health care organizations and in the current study multiple events occurred during the study period plausibly affecting the results. Our findings suggest that the process of implementing structural change in an orthopaedic spine surgery care unit slightly reduces resistance to change but maintains the discrepancy between current and preferred organizational cultures. The amplified demand for PCC entails structural change, but as seen in the current study structural change is not enough and does not automatically lead to cultural change. Relational change is likewise required. The clinical relevance and importance of the current study within quality improvement is that implementation of change needs to combine the structural as well as the relational aspect of change.

\section{Abbreviations}

RTC: Resistance to change; OC: Organizational culture; HCOs: Health care organizations; PCC: Person-centred care; i-PARIHS: The Integrated Promoting Action on Research Implementation in Health Services; RN: Registered nurses; PT: Physiotherapists; AN: Assistant nurses; CVF: Competing Values

Framework; CC: The clan culture; AC: The adhocracy culture; MC: The market culture; HC: The hierarchy culture; RTCS: Resistance to Change Scale;

RS: Routine seeking; ER: Emotional reaction to imposed change; STF: Short- 
term focus; CR: Cognitive rigidity; SD: Standard deviation; IQR: Interquartile range

\section{Supplementary Information}

The online version contains supplementary material available at https://doi. org/10.1186/s12913-021-06819-0.

\section{Additional file 1.}

Additional file 2.

\section{Acknowledgements}

The authors thank the HCPs for their participation. Thanks to Les Hearn (Scientific Proofreading and Editing).

\section{Authors' contributions}

$\mathrm{EA}, \mathrm{HW}, \mathrm{HB} ; \mathrm{AB}$ made substantial contributions to conception and design. EA of acquisition of data, and all authors of analysis and interpretation of data. EA and AW were involved in drafting the manuscript. All authors revised the manuscript critically for important intellectual content. All authors gave final approval of the version to be published.

\section{Funding}

This study was financed by grants from the Swedish state under the agreement between the Swedish government and the county councils, the ALF agreement (ID number 238801). The study was also funded by The Hjalmar Svensson Foundation. The funders were not involved in the study design, data collection, data analysis or interpretation of data, nor in writing the manuscript. Open Access funding provided by University of Gothenburg.

\section{Availability of data and materials}

The datasets generated and/or analysed during the current study are not publicly available due the risk this poses to the confidentiality of participants. However, de-identified data is available from the corresponding author on reasonable request.

\section{Declarations}

Ethics approval and consent to participate

The Swedish Ethical Review Authority, The Regional Ethical Review Board in Gothenburg approved the study (ID number 124-16), which conforms to the principles of the Declaration of Helsinki. Informed consent was signed by the participants.

\section{Consent for publication}

Not applicable.

\section{Competing interests}

The authors declare that they have no competing interests.

\section{Author details}

${ }^{1}$ Department of Orthopaedics, Institute of Clinical Sciences, at Sahlgrenska Academy, University of Gothenburg, Gothenburg, Sweden. ${ }^{2}$ Institute of Health and Care Sciences at Sahlgrenska Academy, University of Gothenburg, Gothenburg, Sweden. ${ }^{3}$ Sahlgrenska Universitetssjukhuset Forskningsenhet ortopedi, Länsmansgatan 28, 43180 Mölndal, Sweden. ${ }^{4}$ Department of Quality Improvement, Sahlgrenska University Hospital, Gothenburg, Sweden. ${ }^{5}$ Architecture, Chalmers University of Technology, Gothenburg, Sweden. ${ }^{6}$ Department of Orthopaedics, Sahlgrenska University Hospital, Gothenburg, Sweden

Received: 3 November 2020 Accepted: 23 July 2021

Published online: 11 December 2021

\section{References}

1. Nilsen P, Schildmeijer K, Ericsson C, Seing I, Birken S. Implementation of change in health care in Sweden: a qualitative study of professionals' change responses. Implement Sci. 2019;14(1):51 https://doi.org/10.1186/s13 012-019-0902-6.
2. Peiperl M. Resistance to change. In: Nicholson N, Audia PG, Pillutula MM, editors. The Blackwell encyclopedia of management. Organizational behaviour. Oxford: Blackwell; 2005. p. 348-9.

3. Coch L, French JR Jr. Overcoming resistance to change. Hum Relat. 1948; 1(4):512-32.

4. Lewin K. Group decision and social change. Readings Soc Psychol. 1947;3(1): 197-211.

5. Schein EH. Organizational culture and leadership. San Fransisco: Wiley; 2010

6. Davies HT, Nutley SM, Mannion R. Organisational culture and quality of health care. BMJ Qual Saf. 2000;9(2):111-9.

7. Michie S, Williams S. Reducing work related psychological ill health and sickness absence: a systematic literature review. Occup Environ Med. 2003; 60(1):3-9 https://doi.org/10.1136/oem.60.1.3

8. Carlström E, Olsson L-E. The association between subcultures and resistance to change-in a Swedish hospital clinic. J Health Organ Manag. 2014;28(4): 458-76 https://doi.org/10.1108/JHOM-09-2012-0184.

9. Ekman I, Swedberg K, Taft K, Lindseth A, Norberg A, Brink E, et al. Personcentered care: ready for prime time. Eur J Cardiovasc Nurs. 2011;10(4):24851 https://doi.org/10.1016/j.ejcnurse.2011.06.008.

10. Naldemirci Ö, Wolf A, Elam M, Lydahl D, Moore L, Britten N. Deliberate and emergent strategies for implementing person-centred care: a qualitative interview study with researchers, professionals and patients. BMC Health Serv Res. 2017:17(1):1-10.

11. Moore L, Britten N, Lydahl D, Naldemirci Ö, Elam M, Wolf A. Barriers and facilitators to the implementation of person-centred care in different healthcare contexts. Scand J Caring Sci. 2017;31(4):662-73 https://doi.org/1 $0.1111 /$ scs. 12376

12. Alharbi T, Carlström E, Ekman I, Olsson L-E. Implementation of personcentred care: management perspective. J Hosp Admin. 2014;3(3):107-20.

13. Wolf A, Ulin $\mathrm{K}$, Carlström $\mathrm{E}$. Changing the ward culture in a clinic during the implementation of person-centred care. J Hosp Admin. 2017;6(5):31 https:// doi.org/10.5430/jha.v6n5p31.

14. Angelini E, Wijk H, Brisby $H$, Baranto A. Patients' experiences of pain have an impact on their pain management attitudes and strategies. Pain Manag Nurs. 2018;19(5):464-73.

15. Angelini E, Baranto A, Brisby H, Wijk H. Healthcare practitioners' experiences of postoperative pain management in lumbar spine surgery care-a qualitative study. J Clin Nurs. 2020;29(9-10):1662-72 https://doi.org/10.1111/ jocn. 15230 .

16. Harvey G, Kitson A. PARIHS revisited: from heuristic to integrated framework for the successful implementation of knowledge into practice. Implement Sci. 2015;11(1):33 https://doi.org/10.1186/s13012-016-0398-2.

17. National Board of Health and Welfare (Socialstyrelsen). SOSFS 2012: 9 Ändring i föreskrifterna och allmänna råden (SOSFS 2000: 1) om läkemedelshantering i hälso-och sjukvården [Changes in regulations and general advices regarding the handling of drugs in the health care system]. Västerås.

18. Cameron KS, Quinn R. Diagnosing and changing organizational culture: based on the competing values framework. San Fransisco: Wiley; 2011.

19. Oreg S. Resistance to change: developing an individual differences measure. J Appl Psychol. 2003;88(4):680-93 https://doi.org/10.1037/0021-9010.88.4. 680.

20. Heritage $B$, Pollock $C$, Roberts $L$. Validation of the organizational culture assessment instrument. PLoS One. 2014;9(3):e92879.

21. Bellot J. Defining and assessing organizational culture. In: Nursing forum 2011 Jan (Vol. 46, No. 1). Malden: Blackwell Publishing Inc; 2011. p. 29-37.

22. Mokkink LB, Terwee CB, Patrick DL, Alonso J, Stratford PW, Knol DL, et al. COSMIN checklist manual. Amsterdam: University Medical Center; 2012.

23. Association GAotWM. World medical association declaration of Helsinki: ethical principles for medical research involving human subjects. J Am Coll Dent. 2014:81(3):14-8.

24. Mannion R, Davies H. Understanding organisational culture for healthcare quality improvement. BMJ. 2018;363:k4907.

25. Nilsen P, Bernhardsson S. Context matters in implementation science: a scoping review of determinant frameworks that describe contextual determinants for implementation outcomes. BMC Health Serv Res. 2019; 19(1):189 https://doi.org/10.1186/s12913-019-4015-3.

26. Jones SL, Van de Ven $\mathrm{AH}$. The changing nature of change resistance: an examination of the moderating impact of time. J Appl Behav Sci. 2016;52(4): 482-506 https://doi.org/10.1177/0021886316671409. 
27. Aarons GA, Ehrhart MG, Farahnak LR, Sklar M. Aligning leadership across systems and organizations to develop a strategic climate for evidencebased practice implementation. Annu Rev Public Health. 2014;35(1):255-74 https://doi.org/10.1146/annurev-publhealth-032013-182447.

28. Ekman I, Wolf A, Olsson LE, Taft C, Dudas K, Schaufelberger M, et al. Effects of person-centred care in patients with chronic heart failure: the PCC-HF study. Eur Heart J. 2012;33(9):1112-9 https://doi.org/10.1093/eurheartj/ehr3 06.

29. Dent EB, Goldberg SG. Challenging "resistance to change". J Appl Behav Sci. 1999;35(1):25-41 https://doi.org/10.1177/0021886399351003.

30. Ford JD, Ford LW, D'Amelio A. Resistance to change: the rest of the story Acad Manage Rev. 2008;33(2):362-77 https://doi.org/10.5465/amr.2008.311 93235.

31. Oreg $\mathrm{S}$. Resistance to change and performance: toward a more evenhanded view of dispositional resistance. J Appl Behav Sci. 2018;54(1):88-107 https://doi.org/10.1177/0021886317741867.

32. Amarantou V, Kazakopoulou S, Chatzoudes D, Chatzoglou P. Resistance to change: an empirical investigation of its antecedents. Journal of Organizational Change Management. 2018;31(2):426-50.

33. Mannion R, Konteh F, Davies H. Assessing organisational culture for quality and safety improvement: a national survey of tools and tool use. BMJ Qual Saf. 2009;18(2):153-6 https://doi.org/10.1136/qshc.2007.024075.

34. Koen B, Loosveldt G, Vandenplas C, Stoop I. Response rates in the European social survey: increasing, decreasing, or a matter of fieldwork efforts? Survey Methods: Insights Field. 2018:1-12.

\section{Publisher's Note}

Springer Nature remains neutral with regard to jurisdictional claims in published maps and institutional affiliations.

Ready to submit your research? Choose BMC and benefit from:

- fast, convenient online submission

- thorough peer review by experienced researchers in your field

- rapid publication on acceptance

- support for research data, including large and complex data types

- gold Open Access which fosters wider collaboration and increased citations

- maximum visibility for your research: over $100 \mathrm{M}$ website views per year

At $\mathrm{BMC}$, research is always in progress.

Learn more biomedcentral.com/submissions 